\title{
Achaete-Scute Homologue 2-Regulated Follicular Helper T Cells Promote Autoimmunity in a Murine Model for Sjögren Syndrome
}

\author{
Kunihiro Otsuka, ${ }^{\dagger \dagger}$ Akiko Yamada, ${ }^{*}$ Masako Saito, ${ }^{\ddagger}$ Aya Ushio, ${ }^{*}$ Mami Sato, ${ }^{*}$ Satoru Kisoda, ${ }^{*}$ Wenhua Shao, ${ }^{*}$ \\ Takaaki Tsunematsu, ${ }^{*}$ Yasusei Kudo, ${ }^{*}$ Rieko Arakaki, ${ }^{*}$ and Naozumi Ishimaru*
}

From the Departments of Oral Molecular Pathology* and Immunology and Parasitology, ${ }^{\ddagger}$ Tokushima University Graduate School of Biomedical Sciences, Tokushima; and the Department of Interdisciplinary Researches for Medicine and Photonics, ${ }^{\dagger}$ Institute of Post-LED Photonics, Tokushima University, Tokushima, Japan

\author{
Accepted for publication \\ August 26, 2019. \\ Address correspondence to \\ Naozumi Ishimaru, D.D.S., \\ Ph.D., Department of Oral \\ Molecular Pathology, Tokush- \\ ima University Graduate School \\ of Biomedical Sciences, 3-18- \\ 15 Kuramoto-cho, Tokushima \\ 7708504, Japan. E-mail: \\ ishimaru.n@tokushima-u.ac.jp.
}

\begin{abstract}
Follicular helper T (Tfh) cells contribute to various immune responses as well as to the pathogenesis of several immune diseases. However, the precise mechanism underlying the onset or development of autoimmunity via Tfh cells remains unclear. Herein, the detailed relationship between autoimmune disease and Tfh cells was analyzed using a murine model for Sjögren syndrome (SS) wherein the mice underwent neonatal thymectomy. Germinal center (GC) development was promoted in this SS model along with an increase of Tfh cells and GC B cells. The severity of the autoimmune lesions was correlated with the number of Tfh cells detected in the spleen of the SS model mice. In addition, treatment with an anti-CD20 monoclonal antibody effectively suppressed the autoimmune lesions with a reduction of Tfh cells and GC B cells. Comprehensive gene analysis revealed that several genes associated with Tfh cell differentiation, including achaete-scute homologue 2 (Ascl2), were up-regulated in peripheral CD25 $\mathrm{CD}^{+} \mathrm{T}$ cells in SS model mice compared with those in control mice. Moreover, an experiment using $C D 4^{C r e} B c l \sigma^{f l f l}$ mice that received neonatal thymectomy treatment demonstrated that Ascl 2 contributes to the Tfh cell differentiation associated with autoimmunity during the early stages, independent of Bcl6. In conclusion, our results indicate that abnormal Tfh cell differentiation via Ascl2 regulation might contribute to the pathogenesis of autoimmunity. (Am J Pathol 2019, 189: 2414-2427; https:/) doi.org/10.1016/j.ajpath.2019.08.008)
\end{abstract}

Follicular helper $\mathrm{T}(\mathrm{Tfh})$ cells are essential for germinal center (GC) formation, affinity maturation, and high-affinity antibody production. ${ }^{1-3}$ Several studies have demonstrated that Tfh cells as well as other helper T-cell subsets influence various immune responses, including autoimmunity and infection. ${ }^{4,5}$ However, the precise mechanism underlying the onset or development of autoimmunity related to $\mathrm{Tfh}$ cells in the peripheral immune system remains unclear.

Sjögren syndrome (SS) is an autoimmune disease, which is generally considered as T cell and B cell mediated, affecting the lacrimal and salivary exocrine glands. The primary clinical symptoms consist of sicca syndrome, including dry eyes and mouth. ${ }^{6,7}$ In addition, SS often accompanies other systemic autoimmune diseases, such as pulmonary lesions, rheumatoid arthritis, and lupus. ${ }^{8,9}$ Several autoantigens have been reported in human and murine SS models, ${ }^{10-13}$ and the relationship between autoreactive $\mathrm{T}$ cells and autoantigens within SS has previously been described. ${ }^{10-13}$ Moreover, anti-Ro/SSA and anti-La/SSB autoantibodies are widely known to be clinically useful in SS diagnosis. ${ }^{14}$ The complicated mechanisms underlying SS further complicate the radical therapy, on the basis of the etiology for patients with SS.

Tfh cells are increased in the peripheral blood and target organs of patients with SS, along with enhanced memory B cells and GC B cells in the target tissues, but not in the

Supported by the Japan Society for the Promotion of Science (JSPS) Grants-in-Aid for Scientific Research 16H02690 and 18K19648 (N.I.).

Disclosures: None declared. 
peripheral blood. ${ }^{15-18}$ Therefore, Tfh cells have been emphasized on for understanding the pathogenesis of SS. On histologic evaluation, ectopic GC formation is observed in the salivary gland tissues of patients with SS by histologic analysis $^{19}$; this formation is associated with the development and outcome of B-cell lymphoma. ${ }^{20-22}$ However, a recent report demonstrates that the presence of $\mathrm{GC}$ formation in minor salivary glands of patients with SS is not correlated to the development of non-Hodgkin lymphoma. ${ }^{23}$ In addition, a previous study has demonstrated that a large number of Tfh cells were detected in the peripheral blood of patients with SS at the time of disease onset, with aberrations of serum anti-Ro/ SSA and anti-La/SSB levels. ${ }^{18}$ Moreover, C-X-C chemokine receptor type $5(\mathrm{CXCR} 5)^{+} \mathrm{CD} 4^{+} \mathrm{Tfh}$ cells are significantly elevated in the salivary gland tissues and peripheral blood of patients with SS, along with aberrant B cells and plasma cells, suggesting that $\mathrm{CXCR}^{+}{ }^{+} \mathrm{CD} 4^{+} \mathrm{Tfh}$ cells contribute to the pathogenesis of SS by promoting B-cell maturation. ${ }^{24}$ In addition, programmed cell death-1 (PD-1) ${ }^{+}$inducible costimulatory-positive Tfh cells in peripheral blood are associated with disease activity of primary SS. ${ }^{25}$ Recent studies have described Bcl6 mRNA expression levels as being significantly higher in the ectopic GC of the salivary gland tissues from patients with SS. ${ }^{26}$ In addition to CXCR5, CD84 and PD-1 expression were also detected on infiltrating lymphocytes in the salivary gland tissues of these patients. ${ }^{26}$ However, the precise cellular or molecular mechanism underlying the pathogenesis of SS via Tfh cells has not yet been clarified.

In the present study, we investigated the mechanism via which Tfh cells contribute to the breakdown of peripheral immune tolerance and the formation of autoimmune lesions in an SS murine model. Our results indicate an autoreactive response mechanism of Tfh cells in an SS murine model, which has not yet been reported, to the best of our knowledge; these results would be supportive for understanding the pathogenesis of autoimmunity.

\section{Materials and Methods}

\section{Mice}

NFS/sld mice were obtained from the Central Institute for Experimental Animals (Kawasaki, Japan). C57BL/6 mice were obtained from the Japan SLC Laboratory (Shizuoka, Japan). $C D 4^{C r e}$ mice were obtained from Taconic (Germantown, NY), and $B c l b^{f l f l}$ mice $^{27}$ were obtained from RIKEN BioResource Center (Tsukuba, Japan). $C D 4^{C r e}$ and $B c l 6^{A / f t}$ mice were mated to generate $C D 4^{C r e} B c l b^{A l f l}$ mice. Thymectomy (Tx) surgery was performed on female NFS/sld, $\mathrm{C} 57 \mathrm{BL} / 6, \mathrm{CD} 4^{\mathrm{Cre}} \mathrm{Bcl6^{+/+ }}$, and $\mathrm{CD} 4^{\mathrm{Cre}} \mathrm{Bcl6^{A/fl }}$ mice at day 3 after birth via a suction technique employing an aspirator. At 4 weeks after the Tx surgery, peripheral blood mononuclear cells from the tail vein were analyzed using flow cytometry. The completeness of Tx surgery was confirmed by evaluating the proportion of CD90.2 $2^{+}$T cells $(<7 \%)$. NFS/sld mice that underwent Tx surgery are defined as SS model mice in the present study. Sham operation (control) in this research is thoracotomy without excision of thymus tissue. The present study was conducted following the Fundamental Guidelines for Proper Conduct of Animal Experiments and Related Activities in Academic Research Institutions under the jurisdiction of the Ministry of Education, Culture, Sports, Science, and Technology of Japan. The protocol was approved by the Committee on Animal Experiments of Tokushima University and the Biological Safety Research Center (permit number T29-115). Experiments were performed under general anesthesia, and all efforts were made to minimize suffering. Mice ages 4 to 30 weeks (NFS/sld) and 20 to 24 weeks $\left(\mathrm{C} 57 \mathrm{BL} / 6, \mathrm{CD} 4^{\mathrm{Cre}} \mathrm{Bcl6^{+/+ }}\right.$, and $\mathrm{CD} 4^{\mathrm{Cre}}$ $B c l \sigma^{A / f l}$ ) were used in the present study.

\section{Histologic Evaluations}

After the mice were sacrificed, all the organs were removed and fixed using 10\% phosphate-buffered formalin ( $\mathrm{pH} 7.2)$. Formalin-fixed tissue sections of salivary glands, cervical lymph nodes, and spleen were stained using hematoxylin and eosin. The number of lymphocytes that infiltrated into submandibular gland tissues per $\mathrm{mm}^{2}$ was determined using hematoxylin and eosin-stained sections.

\section{Immunohistochemistry}

Deparaffinized sections from spleen were used. Heatinduced antigen retrieval was performed in ImmunoActive antigen retrieval solution ( $\mathrm{pH}$ 6.0) (Matsunami Glass, Osaka, Japan) with microwave thrice for 5 minutes. Biotinylated peanut agglutinin (PNA; Vector Laboratories, Burlingame, CA) was applied to the sections; the sections were then incubated overnight at $4^{\circ} \mathrm{C}$. After washing with phosphate-buffered saline, the sections were incubated with horseradish peroxidase-conjugated streptavidin solution (Dako, Carpinteria, CA). Horseradish peroxidase reacted with the 3,3'-diaminobenzidine substrate using the Histofine 3, $3^{\prime}$-diaminobenzidine substrate kit (Nichirei Biosciences, Tokyo, Japan). The sections were counterstained with hematoxylin.

\section{Confocal Analysis}

Frozen spleen tissue sections were fixed using $4 \%$ paraformaldehyde in phosphate-buffered saline and blocked using Blocking One Histo (Nacalai Tesque, Kyoto, Japan). For GC staining, sections were stained using fluoresceinlabeled PNA (Vector Laboratories) and biotinylated antibody against IgD (BioLegend, San Diego, CA), followed by Alexa Fluor 568-conjugated streptavidin (Invitrogen, Carlsbad, CA). After washing thrice with phosphate-buffered saline, nuclear DNA was stained using DAPI (Invitrogen). Sections were observed with a PASCAL confocal laser-scanning microscope (Carl Zeiss, Jena, Germany) at $\times 400$ magnification. 
The laser-scanning microscope image browser version 3.5 (Carl Zeiss) was used for image acquisition.

\section{Enzyme-Linked Immunosorbent Assay}

The autoantibody titers in mice sera were measured using enzyme-linked immunosorbent assays, as previously described. $^{26}$ In brief, the Ro/SS-A (ImmunoVision, Springdale, AR), La/SS-B (ImmunoVision), or $\alpha$-fodrin $(\mathrm{JS}-1)^{28}$ antigens were added to microtiter wells at a concentration of $0.5,1$, or $10 \mu \mathrm{g} / \mathrm{mL}$, respectively, in carbonatebicarbonate buffer (Sigma-Aldrich, St. Louis, MO). Non-specific sites were absorbed using Blocking One (Nacalai Tesque). Plates were washed, and diluted sera were added. Horseradish peroxidase-conjugated anti-mouse IgG $(\mathrm{H}+\mathrm{L})$ (Vector Laboratories) was used as the secondary antibody, and phosphate-citrate buffer containing o-phenylenediamine dihydrochloride tablets (Sigma-Aldrich) and hydrogen peroxide (Wako Pure Chemical Industries, Osaka, Japan) was added. The OD at $490 \mathrm{~nm}$ for each well was measured using a microplate reader (Bio-Rad Laboratories, Richmond, CA).

\section{Flow Cytometry Analysis}

Lymphocytes from the spleen were stained with fluoresceinlabeled PNA (Vector Laboratories) and antibodies against fluorescein isothiocyanate-conjugated anti-mouse CD62L (eBioscience, San Diego, CA) and CD21 (BD Biosciences, San Jose, CA); phycoerythrin-conjugated anti-mouse CD23 (TONBO Biosciences, San Diego, CA); peridinin chlorophyll protein-cyanine 5.5 (Cy5.5)-conjugated anti-mouse CD44 (TONBO Biosciences), CD3 (TONBO Biosciences), and CD45.2 (TONBO Biosciences); phycoerythrinCy7-conjugated anti-mouse CD45.2 (TONBO Biosciences); allophycocyanin-conjugated anti-mouse CD4 (TONBO Biosciences), GL-7 (BioLegend), and CD11c (BioLegend); allophycocyanin-Cy7-conjugated CD19 (BioLegend) and CD62L (BioLegend); and Alexa Fluor 780-conjugated anti-mouse PD-1 (eBioscience; using Armenian hamster IgG as an isotype control; eBioscience). For CXCR5 staining, biotinylated anti-mouse CXCR5 (BD Biosciences; using rat IgG2b as an isotype control; BioLegend) and peridinin chlorophyll protein-Cy5.5-conjugated streptavidin (eBioscience) were used. Intracellular forkhead box protein P3 (Foxp3) and achaete-scute homologue 2 (Ascl2) expression was analyzed using an intracellular Foxp3 detection kit (eBioscience), according to the manufacturer's instructions. For Foxp3 intracellular staining, fluorescein isothiocyanate- or phycoerythrin-conjugated anti-mouse/human Foxp3 (eBioscience) was used, whereas for Ascl2 intracellular staining, rabbit anti-mouse/human Ascl2 (Biorbyt, Cambridge, UK) was used as primary antibody (with rabbit IgG as an isotype control; MBL, Nagoya, Japan) and phycoerythrin-conjugated goat anti-rabbit IgG (Santa Cruz Biotechnology, Dallas, TX) was used as secondary antibody. A FACSCanto flow cytometer (BD Biosciences) was used for identifying the cell populations on the basis of the expression profiles. Data were analyzed using FlowJo FACS Analysis software version 10.5.3 (R\&D Systems, Minneapolis, MN). Cell numbers of each subset were calculated by cell counter and flow cytometer and showed within total CD $45.2^{+}$cells in a spleen tissue.

\section{Real-Time Quantitative RT-PCR}

The splenic $\mathrm{CD}^{+}{ }^{+} \mathrm{T}$ cells were purified using EasySep mouse $\mathrm{CD} 4^{+}$T-cell purification kits (Stemcell Technologies, Vancouver, $\mathrm{BC}$, Canada), and splenic $\mathrm{CD} 25^{-} \mathrm{CD} 4^{+} \mathrm{T}$ cells were isolated using purified rat anti-mouse CD25 (eBioscience) and Dynabeads sheep anti-rat IgG (Invitrogen). Total RNA was extracted from purified $\mathrm{CD} 25^{-} \mathrm{CD} 4^{+} \mathrm{T}$ cells using RNeasy Plus Micro kits (Qiagen, Hilden, Germany) and was reverse transcribed. The transcriptions of target genes and $\beta$ actin were generated with a Light Cycler 96 System (Roche, Basel, Switzerland) using TB Green Premix Ex Taq II (Takara Bio, Shiga, Japan) and the following primers: Ascl2, $5^{\prime}$-CGCTGCCCAGACTCATGCCC-3' (forward) and $5^{\prime}$ GCTTTACGCGGTTGCGCTCG- $3^{\prime}$ (reverse); and $\beta$-actin, $5^{\prime}$-GTGGGCCGCTCTAGGCACCA-3' (forward) and $5^{\prime}$ CGGTTGGCCTTAGGGTTCAGGGGG-3' (reverse). Relative $A s c l 2$ mRNA expression was normalized against $\beta$-actin mRNA.

\section{Stimulation of $\mathrm{CD}_{25}{ }^{-} \mathrm{CD}^{+}{ }^{+} \mathrm{T}$ Cells with Anti-CD3/CD28 Antibody}

Purified CD25 ${ }^{-} \mathrm{CD}^{+} \mathrm{T}$ cells $\left(1 \times 10^{5}\right.$ cells/well $)$ were cultured with or without Dynabeads mouse T-activator CD3/ CD28 (Thermo Fisher Scientific, Rockford, IL) at a CD25 $\mathrm{CD}^{+} \mathrm{T}$ cell per bead ratio of 1:0, 1:0.5, or $1: 1$ for 3 days.

\section{Administration of Anti-CD20 Monoclonal Antibody}

Ultra-LEAF purified anti-mouse CD20 antibody $(100 \mu \mathrm{g} /$ dose; BioLegend) was administered weekly via i.v. injection to female SS model mice, aged 7 to 10 weeks. As a control, LEAF purified rat $\operatorname{IgG} 2 \mathrm{~b}, \kappa$ isotype control antibody (100 $\mu \mathrm{g} / \mathrm{dose}$; BioLegend), was administered to SS model mice following the same regimen.

\section{Microarray Analysis}

Total RNA from splenic CD25 ${ }^{-} \mathrm{CD} 4^{+} \mathrm{T}$ cells of control and SS model mice was isolated using an RNeasy Mini Kit (Qiagen). Samples were pooled from four mice for each treatment. The RNA quality was checked using the Bioanalyzer 2100 (Agilent Technologies, Santa Clara, CA). Cy3-labeled cRNA was prepared from 150 ng RNA using the One-Color Low Input Quick Amp Labeling kit (Agilent Technologies), according to the manufacturer's instructions. Cy3-labeled cRNA was hybridized to Agilent Whole Mouse Genome Microarrays $4 \times 44 \mathrm{~K}$ version 2 (Agilent 
Technologies). Slides were scanned immediately after washing on the Agilent DNA Microarray Scanner (Agilent Technologies). The scanned images were analyzed with Feature Extraction software version 10.7.1.1 (Agilent Technologies). All analyses were supported by the Support Center for Advanced Medical Sciences, Tokushima University Graduate School of Biomedical Sciences
(Tokushima, Japan). The data are available online (https:// www.ncbi.nlm.nih.gov/geo; accession number GSE123332).

\section{Statistical Analysis}

Group means were compared using an unpaired $t$-test, and $P<0.05$ was considered significant. The correlations
A

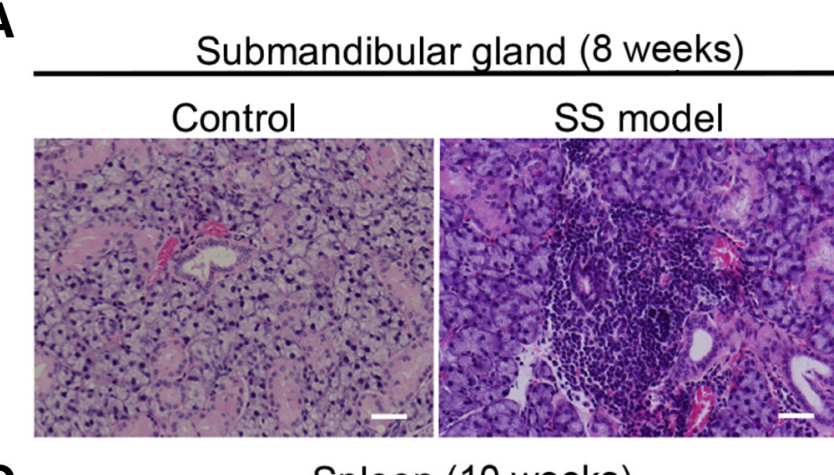

C
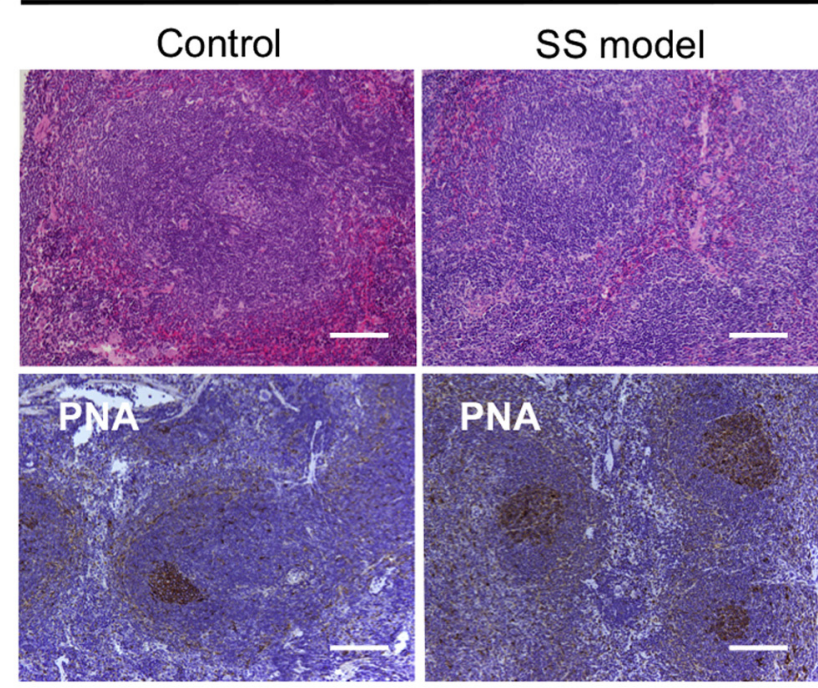

E

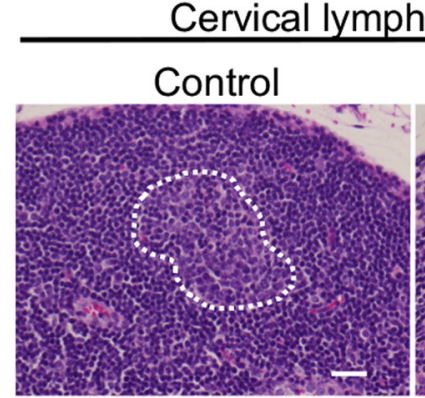

B

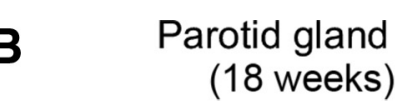

(18 weeks)

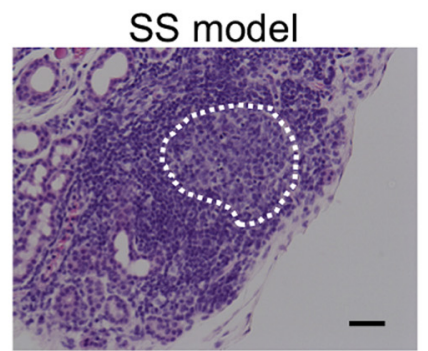

D

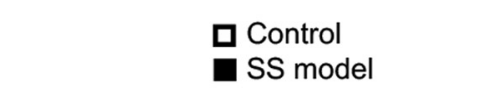

Figure 1 Germinal center (GC) reaction in SS model mice. A: Histology of autoimmune lesions of submandibular glands in SS model mice at 8 weeks of age. Representative images with hematoxylin and eosin staining of control and SS model mice are shown. B: Ectopic lymphoid structure in autoimmune lesions of parotid glands from SS model mice is observed at 18 weeks of age. White dotted line shows GC area. C: GCs of spleen in control and SS model mice at 10 weeks of age. Top panels: Hematoxylin and eosin staining. Bottom panels: Peanut agglutinin (PNA) ${ }^{+} \mathrm{GCs}$. Images are representative of each group. D: PNA ${ }^{+} \mathrm{GC}$ area is presented. E: GCS of cervical lymph nodes from control and SS model mice at 10 weeks of age. Images are representative of each group. White dotted lines show GC area. F: GC reaction was evaluated by confocal microscopic analysis of PNA and IgD expression in the spleen from control and SS model mice at 10 weeks of age. Data are expressed as means \pm SD (D). $n=4$ mice in each group (D); $n=5$ mice in each group (F). ${ }^{\star} P<0.05$. Scale bar $=100 \mu m(\mathbf{A}-\mathbf{C}, \mathbf{E}$, and $\mathbf{F})$. 
between two variables were evaluated with Spearman's rank correlation coefficient.

\section{Results}

\section{GC Reaction in SS Model Mice}

We have previously established an SS murine model using NFS/sld mice that received neonatal Tx. ${ }^{10,29}$ Autoimmune lesions, including lymphocyte accumulation surrounding the extended duct along with the acinar cell destruction, were observed in the submandibular glands, resembling those in patients with SS (Figure 1A). Among the aged SS model mice, inflammatory lesions with GCs were occasionally observed in the parotid glands (Figure 1B), resembling the inflammatory lesions with GC formation observed within the minor salivary glands in patients with SS.
GC formation is detectable in lymphoid tissues, such as the spleen and lymph nodes. The $\mathrm{PNA}^{+} \mathrm{GCs}$ in the spleen of SS model mice were observed to be expanded when compared with those of control mice (Figure 1C). The areas of these expanded GCs were significantly increased compared with those of control mice (Figure 1D). In addition, the GCs within the cervical lymph nodes of SS model mice were expanded compared with those of control mice (Figure 1E). Accumulation of $\mathrm{PNA}^{+} \mathrm{IgD}^{-} \mathrm{GC} \mathrm{B}$ cells and $\mathrm{PNA}^{-} \mathrm{IgD}^{+} \mathrm{B}$ cells within the spleen in the SS model mice was considerably increased compared with that of control mice (Figure 1F). Furthermore, the autoantibody levels of anti-Ro/SSA, anti-La/SSB, and anti- $\alpha$-fodrin antibodies in the sera of SS model mice were significantly elevated compared with those from control mice (Supplemental Figure S1). These results suggest that the enhanced GC reaction observed in this $\mathrm{SS}$ murine model contributes to the
A

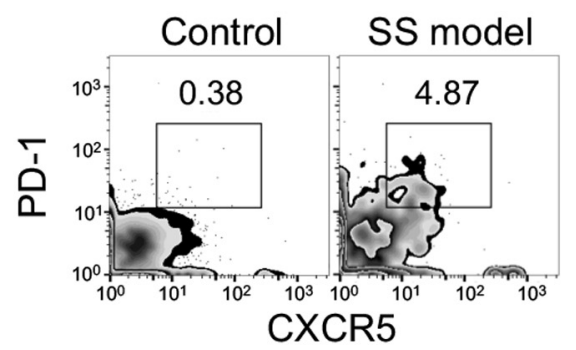

D

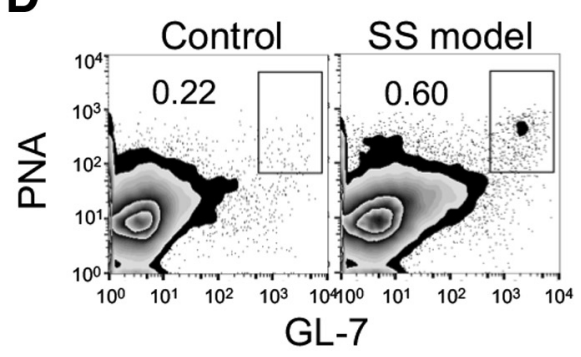

$\mathbf{F}$

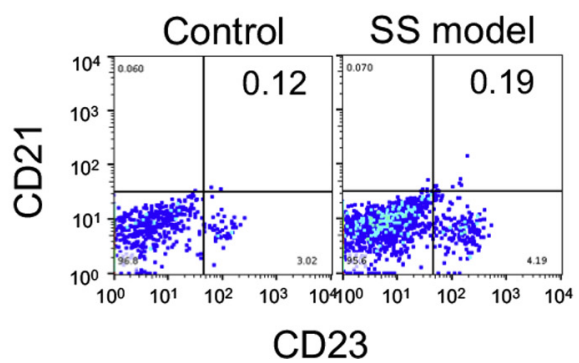

B
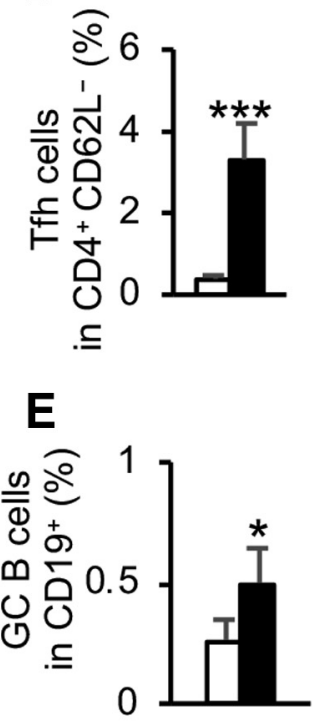

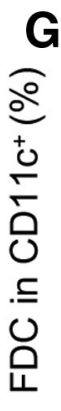
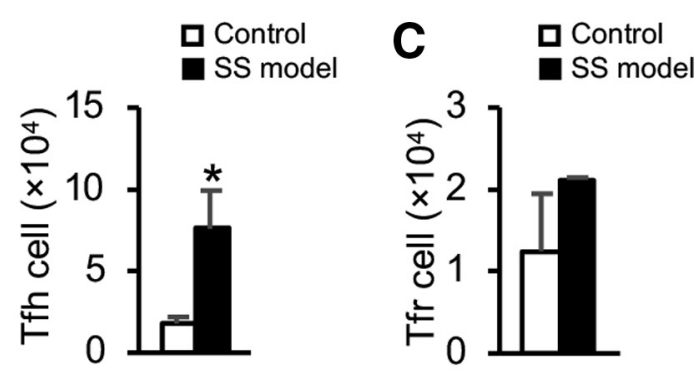

Figure 2 Germinal center (GC) reaction-associated subsets in SS model mice. A: Programmed cell death-1 (PD-1) ${ }^{+}$C-X-C chemokine receptor type 5 $(\mathrm{CXCR5})^{+} \mathrm{CD}_{2} \mathrm{~L}^{-} \mathrm{CD}^{+}$follicular helper T (Tfh) cells from the spleen of control and SS model mice were analyzed using flow cytometry. Results are representative of mice at 8 weeks of age. B: The proportion and number of Tfh cells are presented. C: The number of forkhead box protein P3 (Foxp3) ${ }^{+}$PD- $1^{+}$ $\mathrm{CXCR}^{+} \mathrm{CD}_{2} \mathrm{~L}^{-} \mathrm{CD}^{+}$follicular regulatory T (Tfr) cells is presented. D: Peanut agglutinin (PNA) ${ }^{+} \mathrm{GL}-7^{+} \mathrm{CD} 19^{+} \mathrm{GC} \mathrm{B}$ cells from the spleen of control and SS model mice were analyzed using flow cytometry. Results are representative of mice at 8 weeks of age. E: The proportion and number of GC B cells are presented. F: $\mathrm{CD}_{21}{ }^{+} \mathrm{CD}_{23}{ }^{+} \mathrm{CD} 11 \mathrm{c}^{+}$follicular dendritic cells (FDCs) from the spleen of control and SS model mice were analyzed using flow cytometry. Results are representative of mice at 8 weeks of age. G: The proportion and number of FDCs are presented. Data are expressed as means \pm SD (B, $\mathbf{E}$, and $\mathbf{G})$ or averages $\pm \mathrm{SD}(\mathbf{C}) . n=5$ mice in each group $(\mathbf{A}-\mathbf{G}) .{ }^{*} P<0.05,{ }^{*}{ }^{*} P<0.0005$. 
autoimmunity, including inflammatory lesions, in the target organ as well as to autoantibody production.

\section{GC Reaction and Autoimmunity}

Immune cell populations associated with $\mathrm{GC}$ reactions, including Tfh cells, GC B cells, follicular regulatory T cells, and follicular dendritic cells, were isolated from the spleen of control and SS model mice and analyzed using flow cytometry, according to the gating strategy (Supplemental Figure S2). The proportion and cell number of PD- $1^{+}$ $\mathrm{CXCR}^{+}{ }^{+}$Foxp3 ${ }^{-} \mathrm{CD} 6 \mathrm{~L}^{-} \mathrm{CD} 4^{+}$Tfh cells were significantly higher in SS model mice than in control mice (Figure 2, A and B). No change was observed in the number of PD- $1^{+}$CXCR5 $^{+}$Foxp3 $^{+}$CD62L $^{-} \mathrm{CD}^{+}$follicular regulatory $\mathrm{T}$ cells between the two groups (Figure 2C). In addition, the proportion and cell number of $\mathrm{PNA}^{+} \mathrm{GL}-7^{+}$ CD $19^{+}$GC B cells were significantly enhanced in SS model mice compared with control mice (Figure 2, D and E). Moreover, a significant increase in the number of $\mathrm{CD} 23^{+}$ $\mathrm{CD} 21^{+} \mathrm{CD}^{-} \mathrm{CD}^{-} 9^{-} \mathrm{CD} 11 \mathrm{c}^{+}$follicular dendritic cells of SS model mice was observed compared with that of control mice, but there was no difference in the proportion (Figure 2, F and G). Therefore, the expansion of Tfh cells and GC B cells enhances the GC reaction in the SS model mice. On the other hand, cell numbers of type 1,2, and 17 helper $\mathrm{T}$ cells were not changed between control and SS model mice (Supplemental Figure S3). Otherwise, the cell number of T-regulatory cells in SS model mice was significantly decreased compared with that in control mice (Supplemental Figure S3). Thus, Tfh cells may play a key role in the pathogenesis of autoimmunity in this SS model.

\section{Correlation of Autoimmunity with Tfh Cells}

To elucidate the role of Tfh cells in the severity of autoimmune lesions, correlation between the number of Tfh cells in the spleen and the number of lymphocytes that infiltrated into submandibular glands per $\mathrm{mm}^{2}$ was analyzed using SS model mice from 8 to 30 weeks of age. The number of Tfh cells in the spleen was positively correlated with the severity of autoimmune lesions $(r=0.53, P<0.05)$ (Figure 3A). Conversely, no significant correlation was observed between the number of GC B cells in the spleen and the number of lymphocytes that infiltrated into the submandibular glands per $\mathrm{mm}^{2}$ in this model $(P>0.05)$ (Figure 3B). Furthermore, no correlation was observed between the number of lymphocytes that infiltrated into the submandibular glands per
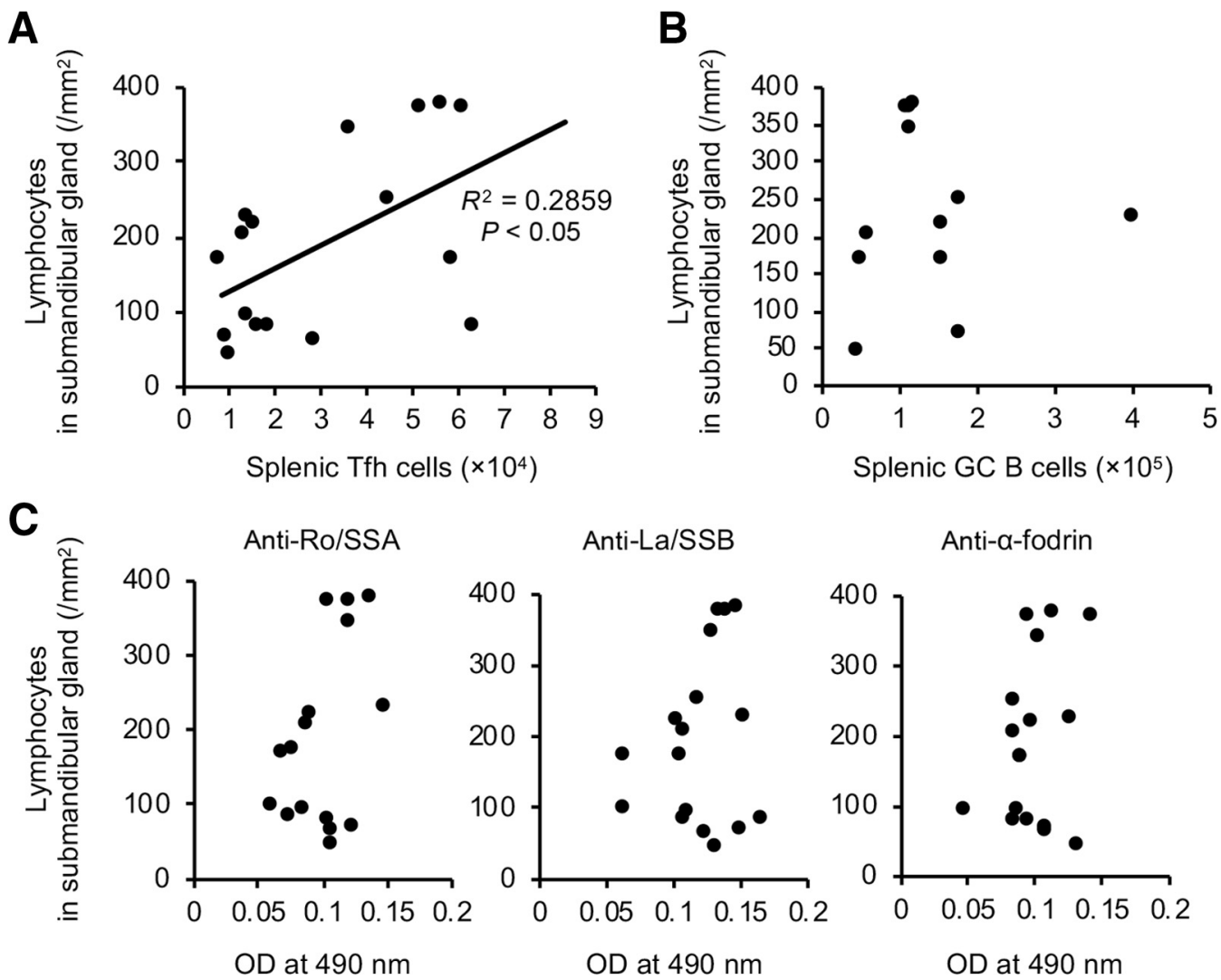

Figure 3 Relationship between the severity of inflammation and follicular helper T (Tfh) cells in SS model mice. Using cells harvested from SS model mice at 8 to 30 weeks of age, statistical analyses were performed concerning the relationships between numbers of lymphocytes that infiltrated into the submandibular gland tissues per $\mathrm{mm}^{2}$ and the number of Tfh cells in the spleen (A), the number of germinal center (GC) B cells in the spleen (B), and serum autoantibody titers against anti-Ro/SSA, anti-La/SSB, and anti- $\alpha$-fodrin $(\mathbf{C}) . R^{2}$ is the coefficient of determination. Black line shows the approximate curve. 
A

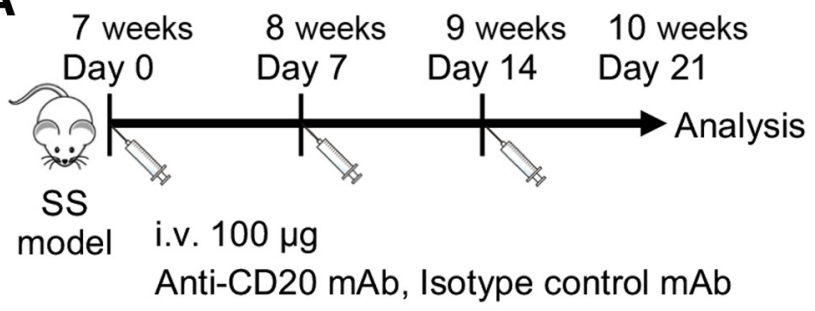

C

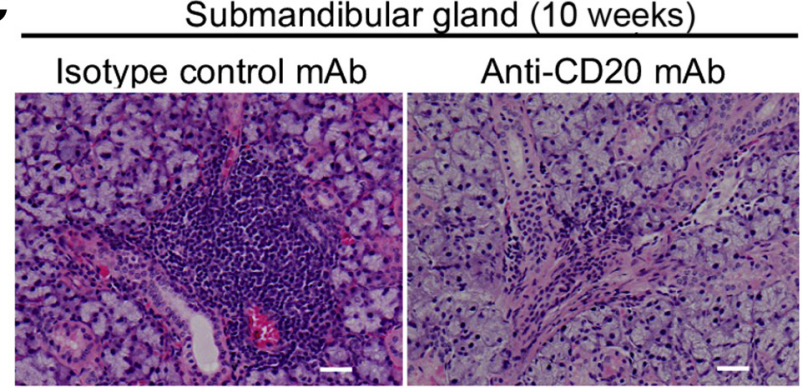

E
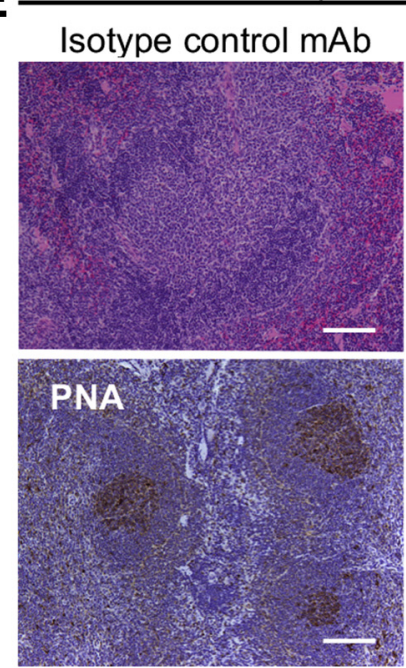

Spleen (10 weeks)
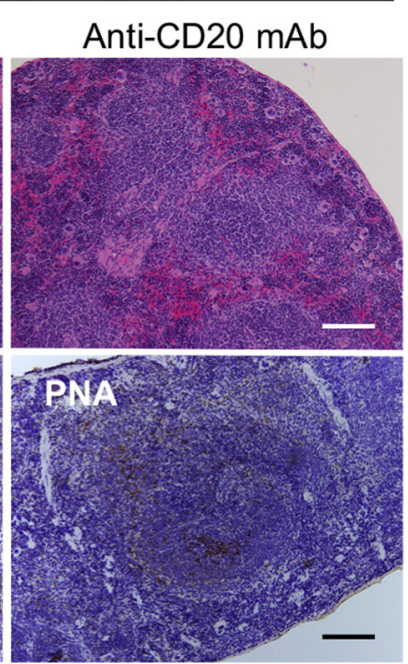

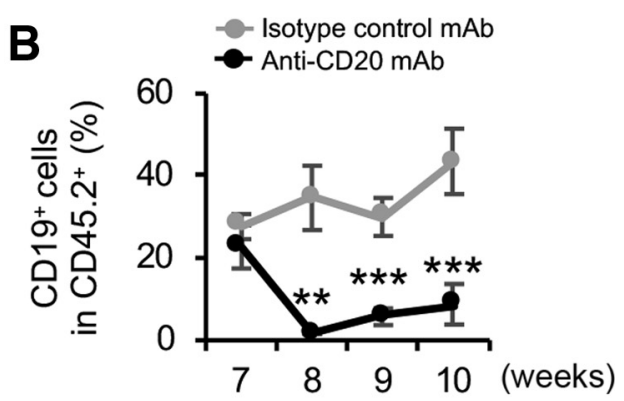

D

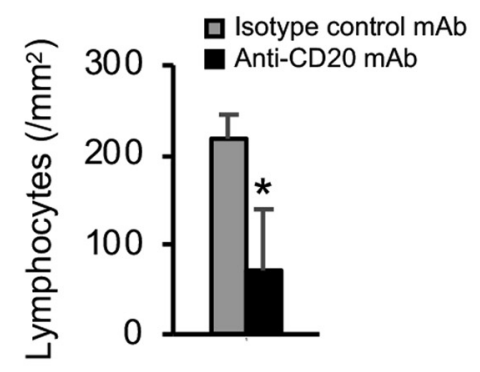

$\mathbf{F}$

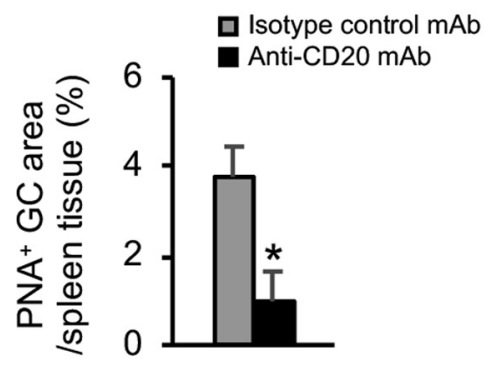

G

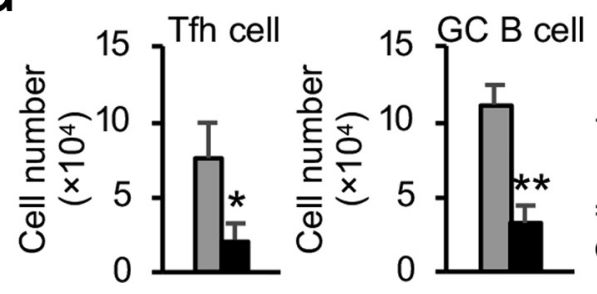

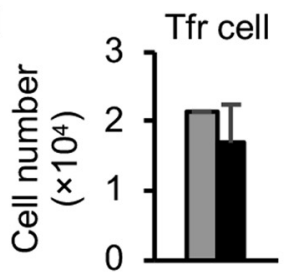

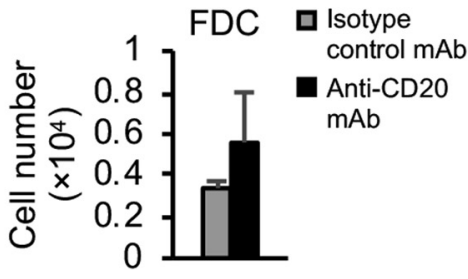

Figure 4 Effect of anti-CD20 monoclonal antibody (mAb) administration on autoimmune lesions and follicular helper T (Tfh) cells in SS model mice. A: Anti-CD20 mAb or isotype control mAb (100 $\mu \mathrm{g} /$ dose) was intravenously injected into SS model mice once a week from 7 to 9 weeks of age, with analysis at 10 weeks of age. B: The proportion of $\mathrm{CD} 19^{+} \mathrm{B}$ cells within CD45.2 ${ }^{+}$cells was analyzed using flow cytometry. C: Histopathologic analysis was performed using the submandibular gland tissues from mice that received isotype control mAb or anti-CD20 mAb-administered mice. D: The number of lymphocytes that infiltrated into the submandibular gland tissues per $\mathrm{mm}^{2}$ was determined from the hematoxylin and eosin-stained sections. E: Germinal centers (GCs) of the spleen in isotype control mAb- or anti-CD20 mAb-administered mice. F: GC area is presented. G: The numbers of Tfh cells, GC B cells, follicular regulatory T (Tfr) cells, and follicular dendritic cells (FDCs) in the spleen of isotype control mAb- or antiCD20 mAb-administered mice were analyzed using flow cytometry. Data are expressed as means \pm SD (B, D, and $\mathbf{F})$ or average \pm SD (G). $n=4$ mice in each group $(\mathbf{B}$ and $\mathbf{D}-\mathbf{G}) ; n=5$ mice in each group $(\mathbf{C}) .{ }^{*} P<0.05,{ }^{*} P<0.005$, and ${ }^{* * *} P<0.0005$. Scale bar $=100 \mu \mathrm{m}(\mathbf{C}$ and $\mathbf{E})$. PNA, peanut agglutinin. 
$\mathrm{mm}^{2}$ and the titer level of autoantibodies, such as anti-Ro/ SSA, anti-La/SSB, and anti- $\alpha$-fodrin autoantibodies $(P>0.05)$ (Figure 3C). These results suggest that Tfh cells within GCs play a key role in the formation of autoimmune lesions within the SS model mice.

\section{Effect of B-Cell Depletion on Tfh Cells in SS Model Mice}

A previous report has demonstrated that therapy using antiCD20 monoclonal antibody ( $\mathrm{mAb}$ ) for B-cell depletion was effective for patients with SS and resulted in a reduced number of Tfh cells. ${ }^{30}$ Therefore, we hypothesized that B-cell depletion may suppress a GC reaction in the SS model mice. Anti-CD20 mAb or rat IgG2b mAb (ie, isotype control) was intravenously administered thrice into SS model mice from 7 to 9 weeks of age, and the mice were analyzed at 10 weeks of age (Figure 4A). The proportion of $\mathrm{CD} 19^{+} \mathrm{B}$ cells within $\mathrm{CD} 45.2^{+}$cells from anti-CD20 $\mathrm{mAb}$-treated mice was significantly reduced compared with that from isotype control $\mathrm{mAb}$-treated mice (Figure 4B). Interestingly, autoimmune lesions within the salivary glands of SS model mice were suppressed by antiCD20 mAb administration (Figure 4C). The number of lymphocytes that infiltrated into the submandibular glands per $\mathrm{mm}^{2}$ of anti-CD20 $\mathrm{mAb}$-treated mice was significantly reduced compared with that of isotype control $\mathrm{mAb}-$ treated mice (Figure 4D). In addition, $\mathrm{PNA}^{+} \mathrm{GCs}$ in the spleen of anti-CD20 mAb-treated mice were considerably diminished compared with those of isotype control $\mathrm{mAb}$-treated mice (Figure 4E). The $\mathrm{PNA}^{+} \mathrm{GC}$ areas of anti-CD20 $\mathrm{mAb}$-treated mice were significantly decreased compared with those of isotype control $\mathrm{mAb}$-treated mice (Figure 4F). Furthermore, the numbers of both Tfh cells and GC B cells in the spleen of anti-CD20 mAb-treated mice were significantly reduced compared with those of isotype control mAb-treated mice (Figure 4G). In contrast, no differences were observed in number of follicular regulatory $\mathrm{T}$ cells and follicular dendritic cells between anti-CD20 $\mathrm{mAb}$-treated mice and isotype control $\mathrm{mAb}$-treated mice (Figure 4G). Furthermore, no changes were noted in the autoantibody levels of anti-Ro/SSA, anti-La/SSB, and anti- $\alpha$-fodrin within the sera between anti-CD20 mAbtreated and isotype control $\mathrm{mAb}$-treated mice (Supplemental Figure S4). These results suggest that antiCD20 mAb treatment is effective on autoimmune lesions in SS model mice and that B-cell depletion suppresses the $\mathrm{GC}$ reaction with a reduction of $\mathrm{Tfh}$ cells in these mice.

\section{Tfh Cell-Related Gene Signature in SS Model Mice}

Tfh cell-related gene expression of splenic CD25- $\mathrm{CD} 4^{+} \mathrm{T}$ cells in SS model mice was comprehensively analyzed by comparison with that in control mice using DNA microarray analysis. Regarding genes that are associated with Tfh cell differentiation, positive regulator genes, such as Ascl2, Il21 isoform 2 precursor, $C x c r 5$, and Il6 isoform 1 precursor, were greater than threefold up-regulated in SS model mice compared with those in control mice (Figure 5A). In contrast, negative regulator genes, such as inhibitor of DNA binding-3 (Id3), PR domain-containing protein $1(\operatorname{Prdml}) / \mathrm{B}$ lymphocyte-induced maturation protein 1 (Blimpl), and STAT5A isoform 1, remained unchanged (Figure 5A). A significantly up-regulated level of Ascl 2 mRNA in CD25 $\mathrm{CD} 4^{+} \mathrm{T}$ cells of $\mathrm{SS}$ model mice was confirmed in comparison with that in control mice from 4 to 20 weeks of age by realtime quantitative RT-PCR (Figure 5B). A significantly increased Ascl2 mRNA expression of $\mathrm{CD}^{+}{ }^{+} \mathrm{T}$ cells was observed in SS model mice compared with control mice at 4 weeks of age when the autoimmune lesions are not observed yet in the target organ (Figure 5B). Ascl2 is known as one of the key transcription factors involved in the early stage of $\mathrm{Tfh}$ cell differentiation for controlling Cxcr5 expression. ${ }^{31}$ The proportion of $\mathrm{Ascl}^{+} \mathrm{CD}^{+} \mathrm{T}$ cells in the spleen of the SS model mice was significantly higher in SS model mice than in control mice (Figure 5, C and D). In addition, CXCR5 expression on $\mathrm{Ascl}^{+} \mathrm{CD}^{+}$cells in the spleen of the SS model mice was also significantly increased compared with that of control mice (Figure 5, E and F). Ascl2 expression is controlled by AKT and Wnt signaling under the CD3/CD28 pathway. ${ }^{31}$ On stimulating $\mathrm{CD} 25^{-} \mathrm{CD} 4^{+} \mathrm{T}$ cells from the spleen of control and SS model mice using anti-CD3/CD28 $\mathrm{mAb}$-coated beads for 3 days, the intracellular Ascl2 expression of $\mathrm{CD}^{+} \mathrm{T}$ cells was significantly enhanced within SS model mice compared with that within controls (Figure 5, $\mathrm{G}$ and $\mathrm{H}$ ). In our experimental system, the suitable condition for Ascl-2 expression was cell/bead ratio of 1:0.5. Perhaps a strong signaling (1:1) of CD3/CD28 may reach to the peak of Ascl 2 expression of $\mathrm{T}$ cells in both control and SS model mice. These results suggest that the Ascl2 up-regulation enhances Tfh cell differentiation to influence an autoimmune reaction in this SS model.

\section{$\mathrm{AsCl}^{+} \mathrm{CD}^{+}$Cells in Thymectomized $\mathrm{CD} 4^{\mathrm{Cre}}$ $B c l 6^{f l f l}$ Mice}

Although Bcl6 is recognized as a master regulatory molecule for Tfh cell differentiation, ${ }^{32}$ the relationship between Bcl6 and Ascl2 within the autoimmune response associated with Tfh cells remains unclear. Therefore, Ascl2 expression of $\mathrm{CD}^{+} \mathrm{T}$ cells was analyzed in C57BL/6-background wild-type (WT) and $C D 4^{C r e} B c l 6^{A l f l}$ mice treated with or without neonatal Tx, which resemble the SS model mice in the present study. Sham-WT or Tx-WT and $C D 4^{C r e} B c l 6^{A f f l}$ mice, aged 20 to 24 weeks, were used to analyze Ascl2 expression in the spleen cells. In WT mice, Ascl2 expression of splenic $\mathrm{CD}^{+} \mathrm{T}$ cells in $\mathrm{Tx}$ mice was significantly higher than that of sham mice (Figure 6A); this finding is consistent with that in SS model mice. In $C D 4^{C r e} B c l 6^{A l f l}$ mice, Ascl 2 expression of splenic $\mathrm{CD} 4^{+} \mathrm{T}$ cells in Tx mice was also significantly higher than that of sham mice (Figure 6, A and B). Moreover, the proportion and number of Tfh cells in the spleen of Tx-WT mice were significantly 
A
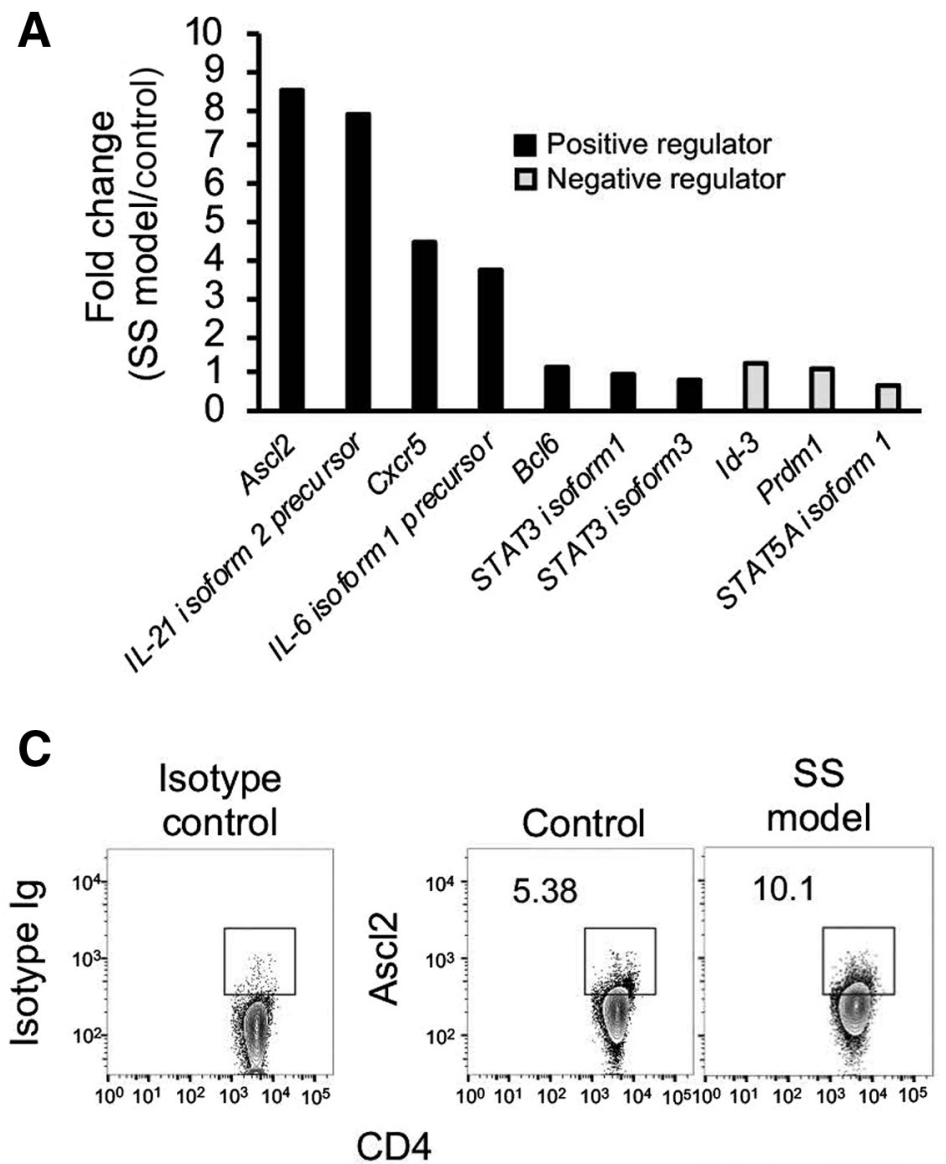

Gated on $\mathrm{CD}^{+}$

E

Isotype control

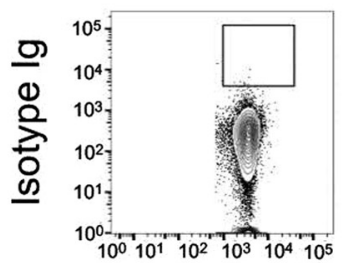
CD4

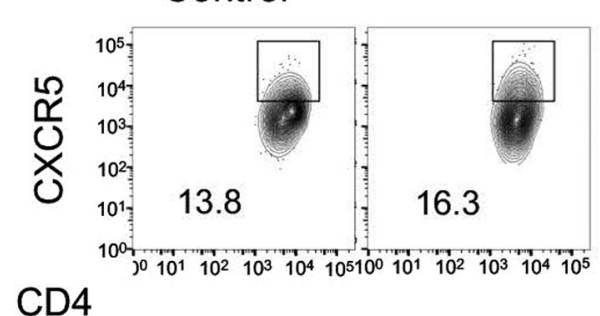

Gated on $\mathrm{CD}^{+}{ }^{+} \mathrm{Ascl} 2^{+}$

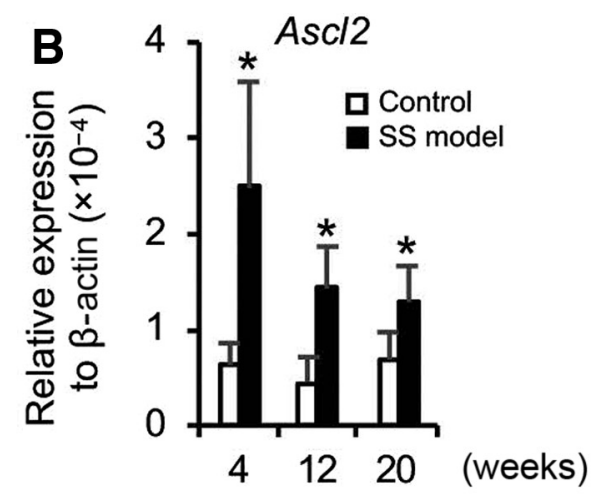

D

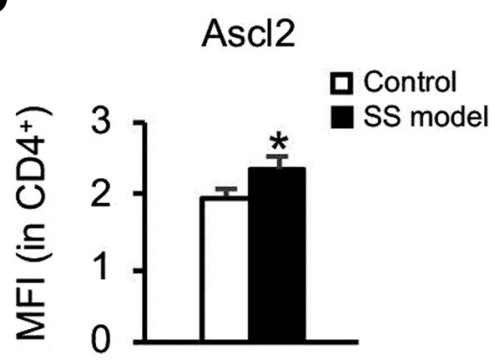

G

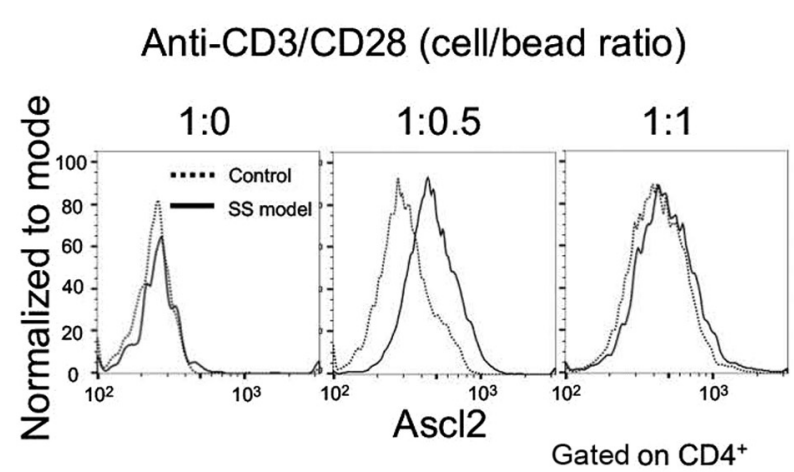

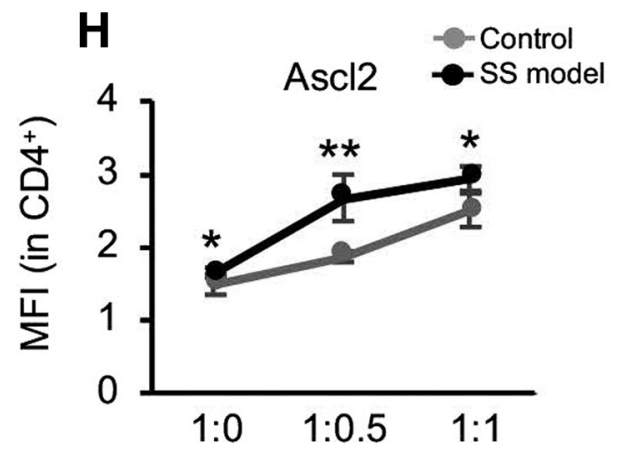

Anti-CD3/CD28 (cell/bead ratio) 
higher than those in sham-WT mice (Figure 6, C and D); these values from both sham-CD4 ${ }^{C r e} B c l 6^{f / f l}$ and Tx-CD4 $4^{C r e}$ $B c l \sigma^{A l f l}$ mice were considerably lower (Figure 6, C and D). Furthermore, the proportion and number of GC B cells in the spleen were significantly higher within Tx-WT than within sham-WT mice (Figure 6, E and F). In contrast, the proportion and number of the splenic GC B cells obtained from both sham-CD4 $4^{C r e} B c l 6^{f / f l}$ and Tx-CD4 $4^{C r e} B c l 6^{f l f t}$ mice remained decreased (Figure 6, E and F). Expression of Ascl 2 was increased in PD- $1^{-} \mathrm{CXCR}^{+} \mathrm{Foxp}^{-} \mathrm{CD} 4^{+}$preTfh cells, and the expression was not changed in Tfh cells (Figure 6, G and H). Therefore, Ascl2 plays a key role in the early stage of Tfh differentiation. In addition, CXCR5 expression of $\mathrm{Ascl}^{+} \mathrm{CD}^{+} \mathrm{T}$ cells was not changed between WT and $\mathrm{CD} 4^{\mathrm{Cre}}$-Bcl6 ${ }^{f l / f}$ mice (Supplemental Figure S5). This result suggests that CXCR5 expression is controlled by Ascl2, independent of Bcl-6. Thus, these results suggest that Ascl2 plays a key role in the early stage of Tfh cell differentiation, whereas Bcl6 is a potent factor during the terminal stage of $\mathrm{Tfh}$ cell differentiation.

\section{Discussion}

In the present study, the relationship between autoimmunity and the GC reaction was investigated using SS model mice. The GC reaction was considerably enhanced along with the increase in the severity of autoimmune lesions in SS model mice. In particular, Tfh cells play a key role in the pathogenesis within these model mice. Positive regulators for Tfh cell differentiation, including Ascl2, of peripheral $\mathrm{CD}^{+}{ }^{+} \mathrm{T}$ cells were up-regulated in SS model mice. The control of the peripheral Tfh cell differentiation may contribute to the onset and development of autoimmunity.

Tfh cells, one of the $\mathrm{CD}^{+}$T-cell subsets capable of activating $B$ cells within the lymphoid organs, play a key role in the formation and maintenance of GCs in secondary lymphoid organs as well as in the regulation of memory B and plasma cell differentiation. ${ }^{1,2}$ Several studies have demonstrated that Tfh cells contribute to a variety of immune responses, including autoimmunity and infection. ${ }^{4}$ Increased numbers of Tfh cells have been reported in the peripheral blood and target organs of patients with SS. ${ }^{33,34}$ CXCR5 is highly expressed on Tfh cells and is a critical chemokine receptor for CXCL13 within homing and signaling pathways. ${ }^{35}$ Cxcr5 expression in Tfh cells is directly controlled by Ascl2, which is one of the important transcription factors during the early stage of Tfh cell differentiation. ${ }^{31}$ Herein, both Ascl2 and CXCR5 protein and gene expression of $\mathrm{CD} 25^{-} \mathrm{CD} 4^{+} \mathrm{T}$ cells were up-regulated in the SS model mice. In addition, gene expression of the other positive regulators of Tfh cell differentiation, such as $I l 21$ and $I l 6$, was enhanced in SS model mice compared with that in control mice. The gene expression of various factors in peripheral $\mathrm{T}$ cells may be impaired in these neonatally thymectomized models. The expansion of T-regulatory cells is impaired via the down-regulation of transforming growth factor- $\beta$ receptor genes in SS model mice. ${ }^{36}$ These findings suggest that the thymic function during the neonatal stage of typical T-cell differentiation contributes to the normal peripheral T-cell differentiation.

Ascl2 is a basic helix-loop-helix transcription factor essential for various cell development processes, such as the trophoblast proliferation maintenance during placental development, nervous system development, somatic stem cell population maintenance, sensory organ development, and Tfh cell differentiation. ${ }^{31,37}$ Ascl 2 directly initiates Tfh cell development by controlling CXCR5 expression. Although Ascl2 may play a key role in the pathogenesis of autoimmunity, no clear evidence concerning the association of Ascl2-regulated Tfh cells with the onset or development of autoimmune disease is available. A recent report has demonstrated that Ascl2 overexpression accelerated SS lesion development in nonobese diabetic/ShiLtJ model mice and that the Ascl2 level was higher in the peripheral blood mononuclear cells obtained from patients with SS compared with those from healthy controls. ${ }^{38}$ Herein, both Ascl2 gene and protein levels within the peripheral $\mathrm{CD} 4^{+} \mathrm{T}$ cells from SS model mice were higher than those of control mice.

Ectopic lymphoid structures are often observed within the inflammatory lesions in the target organs of various autoimmune diseases, such as rheumatoid arthritis, systemic lupus erythematosus, multiple sclerosis, and SS. ${ }^{39}$ Ectopic GCs develop in these chronic inflammatory lesions, thereby controlling antibody diversification, isotype class switching, B-cell differentiation, and oligoclonal expansion, wherein the Tfh cells, GC B cells, follicular dendritic cells, and follicular regulatory $\mathrm{T}$ cells form a network to contribute to an autoimmune response in the target tissues. ${ }^{39}$ These ectopic lymphoid structures are often observed in the salivary gland tissues obtained from patients with $\mathrm{SS}^{19,26}$ and elicit the selection and differentiation of autoreactive B cells

\footnotetext{
Figure 5 Achaete-scute homologue 2 (Ascl2) expression of $\mathrm{CD}^{+}{ }^{+} \mathrm{T}$ cells in SS model mice. A: The mRNA expression of follicular helper T cell-related genes was analyzed with DNA microarray using $\mathrm{CD}_{2} 5^{-} \mathrm{CD}^{+}$splenic T cells in control and SS model mice. Data are presented as pooled samples. B: Ascl2 mRNA expression of $\mathrm{CD}_{25} \mathrm{CD}^{+} \mathrm{T}$ cells in control and SS model mice was analyzed using real-time quantitative RT-PCR. C: Intracellular Ascl2 expression of CD4 ${ }^{+} \mathrm{T}$ cells from the spleen was analyzed using flow cytometry. D: Ascl2 ${ }^{+} \mathrm{CD}^{+}{ }^{+}$T cells from the spleen are presented. E: C-X-C chemokine receptor type 5 (CXCR5) ${ }^{+}$ cells in $\mathrm{Ascl}^{+} \mathrm{CD}^{+} \mathrm{T}$ cells were analyzed using flow cytometry. Results are representative of five mice in each group. $\mathrm{F}: \mathrm{CXCR}^{+}$cells in Ascl2 $2^{+} \mathrm{CD} 4^{+} \mathrm{T}$ cells are presented. G: Ascl2 expression of $\mathrm{CD}^{+}{ }^{+} \mathrm{T}$ cells stimulated with anti-CD3/CD28 monoclonal antibody-coated beads (cell/bead ratio $=1: 0,1: 0.5$, or 1:1) was analyzed using flow cytometry. $\mathrm{H}$ : Ascl2 expression is presented as mean fluorescein intensity (MFI) in $\mathrm{CD}^{+}{ }^{+} \mathrm{T}$ cells from triplicate samples. Data are expressed as means $\pm \mathrm{SD}(\mathbf{A}, \mathbf{B}, \mathbf{D}, \mathbf{F}$, and $\mathbf{H}) . n=4$ mice in each group $(\mathbf{A}) ; n=5$ mice in each group $(\mathbf{B}-\mathbf{D}$ and $\mathbf{F}) ; n=3$ independent experiments $(\mathbf{G}$, using 3 mice in each group, and $\mathbf{H}) .{ }^{*} P<0.05,{ }^{*} P<0.005$.
} 
A

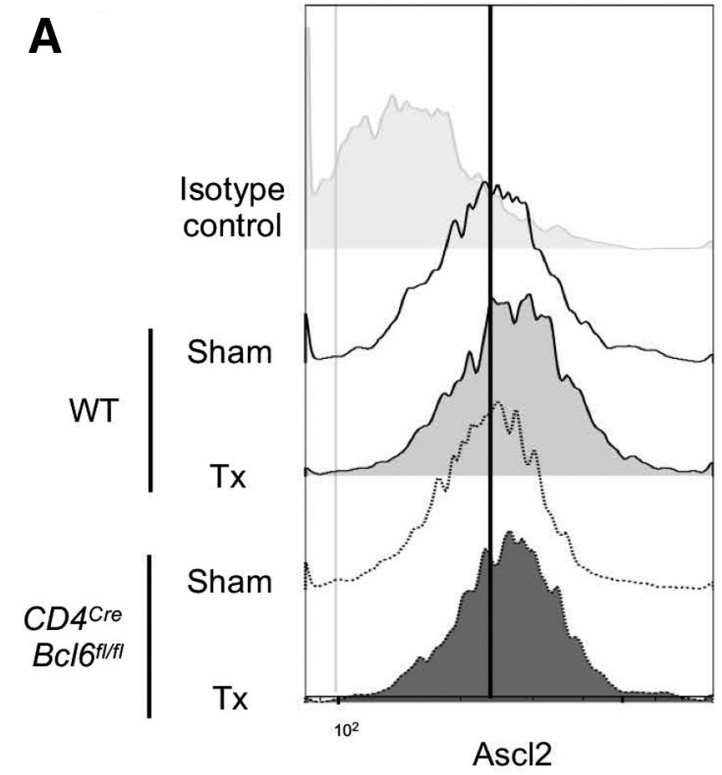

C

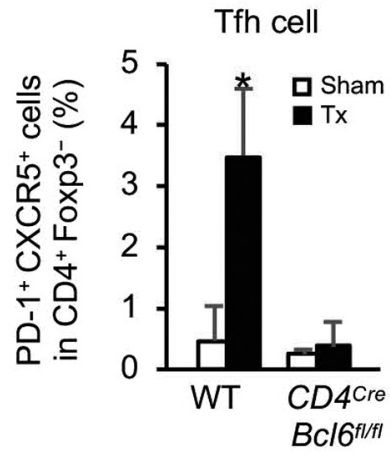

D

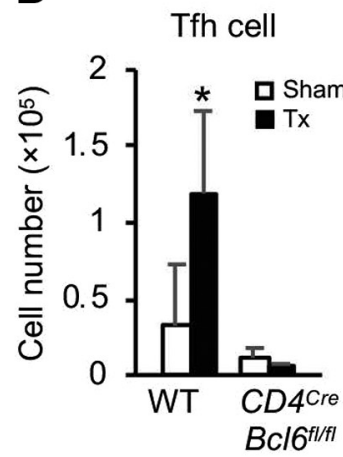

B

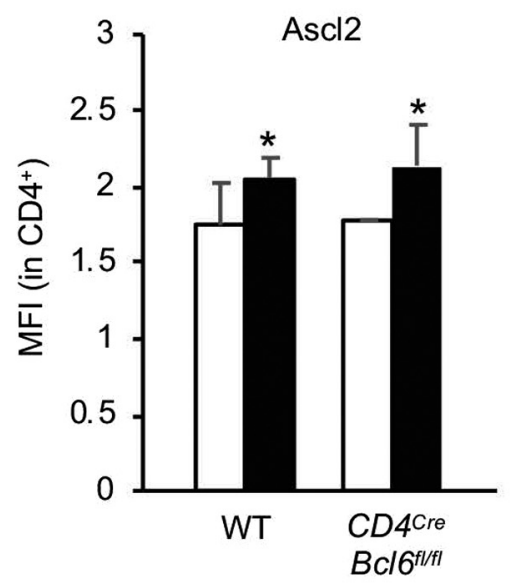

E

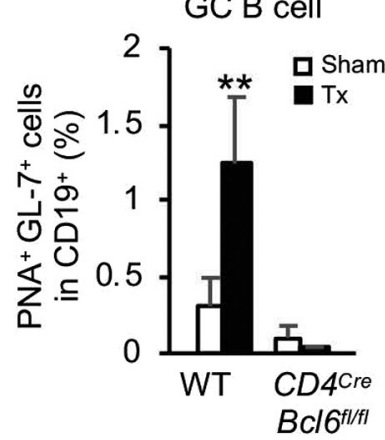

$\mathbf{F}$

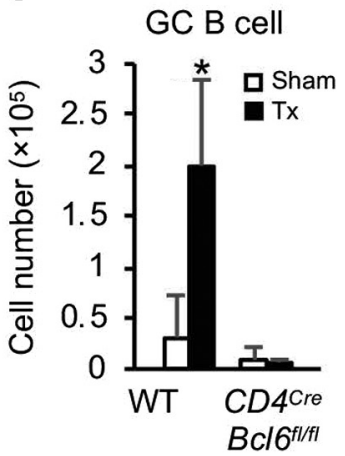

G

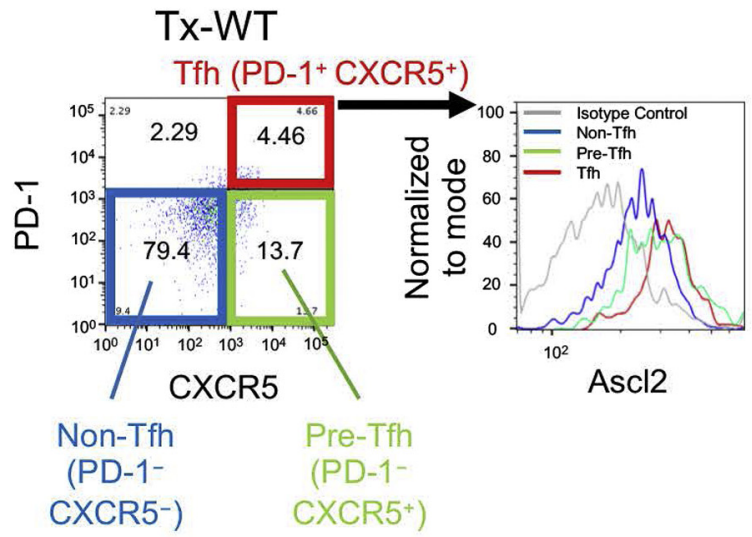

H

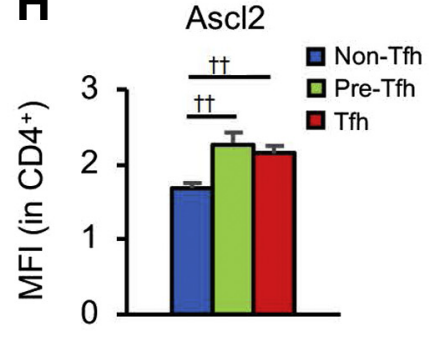

Figure 6 Change of achaete-scute homologue 2 (Ascl2) expression of $\mathrm{CD}^{+}{ }^{+} \mathrm{T}$ cells in wild-type (WT) and $\mathrm{CD} 4^{\mathrm{Cre}} \mathrm{BCl} 6^{\mathrm{fl} f \mathrm{fl}}$ mice treated with neonatal thymectomy (Tx). A: Ascl2 expression of $\mathrm{CD}^{+} \mathrm{T}$ cells in the spleen from WT and $C D 4^{\text {Cre }} B c l 6^{f l f l}$ mice treated with sham or Tx. B: Ascl2 expression is shown as mean fluorescein intensity (MFI) in $\mathrm{CD}^{+}{ }^{\mathrm{T}}$ cells. C: The proportion of follicular helper T (Tfh) cells in the spleen from WT and $C D 4^{\mathrm{Cre}} B c l 6^{f l / f l}$ mice treated with sham or Tx. D: The number of Tfh cells in the spleen from WT and $C D 4^{C r e} B c l 6^{f l f l}$ mice treated with sham or Tx. E: The proportion of germinal center (GC) B cells in the spleen from WT and $C D 4^{C r e} B c l 6^{f l f l}$ mice treated with sham or Tx. F: The number of GC B cells in spleen from WT and $C D 4^{C r e} B C l 6^{f l f l}$ mice treated with sham or Tx. G and $\mathbf{H}$ : Ascl2 expressions of non-Tfh [programmed cell death-1 (PD-1)- C-X-C chemokine receptor type 5 (CXCR5) ${ }^{-}$forkhead box protein P3 (Foxp3) ${ }^{-}$ $\mathrm{CD}^{+}$], pre-Tfh (PD-1 ${ }^{-} \mathrm{CXCR5}^{+}$Foxp $\left.^{-} \mathrm{CD4}^{+}\right)$, and Tfh cells of spleen in Tx C57BL/6 mice were analyzed and were expressed as MFI. Data are expressed as means $\pm \mathrm{SD}(\mathbf{B}-\mathbf{F}$ and $\mathbf{H}) . n=3$ to 5 mice in each group $(\mathbf{A}-\mathbf{F}) ; n=3$ mice $(\mathbf{G}$ and $\mathbf{H}) .{ }^{*} P<0.05,{ }^{* \star} P<0.005$, sham versus Tx; ${ }^{\dagger \dagger} P<0.005$, non-Tfh cell versus pre-Tfh or Tfh cell. PNA, peanut agglutinin. 
into high-affinity plasma cells reacting against the ribonucleoproteins anti-Ro/SSA and anti-La/SSB in $\mathrm{SS}^{24}$ In addition, B-cell lymphoma (ie, mucosa-associated lymphoid tissue lymphoma) occurs at a significantly higher rate in patients with SS. ${ }^{40}$ Moreover, it has been reported that IL-6 and inducible costimulatory ligand expression by salivary gland epithelial cells contributes to naïve $\mathrm{CD} 4^{+} \mathrm{T}$-cell differentiation into Tfh cells. ${ }^{34}$ In our model, the ectopic GCs were observed in the salivary glands of aged mice, in which severe inflammatory lesions were observed. The proportion of Tfh cells in the spleen of the SS model mice was closely related to the disease severity of autoimmune lesions, suggesting that Tfh cells play a key role in the formation or acceleration of these autoimmune lesions, including the ectopic lymphoid structures within interactions with the salivary gland epithelial cells in the target organ. However, it is difficult to explain the detailed relationship between the increased number of Tfh cells in the periphery and the autoimmune lesions of SS model mice. Flow cytometric analysis showed that $\mathrm{Tfh}$ cells were hardly detected in the salivary gland tissues of the SS model mice (K.O., unpublished data), suggesting that Tfh cells play an indirect role in the formation of autoimmune lesions of the target organ. Increased Tfh cells in the periphery may promote autoimmune response in the lymphoid organs, but not the target organ.

In this model, inflammatory lesions are found in the salivary and lacrimal glands from 6 weeks of age. In addition, pulmonary lesions, including lymphocyte infiltration in the interstitial regions around bronchi and blood vessel, are observed from 8 weeks of age, in addition to the inflammatory lesions in lacrimal and salivary glands (A.U., unpublished data). Moreover, rheumatoid arthritis-like lesions are also observed in this aged model of $>12$ months of age. ${ }^{41}$ Autoimmune lesions are well known to be overlapped with multiple organs, such as lung, kidney, and joint. Thus, the inflammatory lesions in this model closely resemble those in patients with SS, and this mouse model has been used for analyzing the pathogenesis and therapeutic studies of SS. ${ }^{36,42,43}$ Moreover, a significant decrease in tear and saliva secretion of this model is observed compared with that in control mice. ${ }^{28,44}$ In addition, although the cell number of Tfh cells in SS model mice was significantly increased compared with that in control mice, cell numbers of type 1,2, and 17 helper T cells were not changed between control and SS model mice. Otherwise, cell number of T-regulatory cells in SS model mice was significantly decreased compared with that in control mice described in a previous report. ${ }^{36}$ However, it has been still unclear why cell number of Tfh cells relates to the severity of autoimmune lesions of salivary glands in this model.

As the pathogenesis of SS is extremely complex, fundamental treatments for this syndrome have not yet been established. ${ }^{6,7,45}$ Treatment with anti-CD20 mAb (eg, rituximab) exhibits effectiveness for improving the lacrimal gland function but not the salivary flow. In addition, no differences were observed at the 24-week evaluation regarding fatigue reduction ( $30 \%$ visual analog scales), serious adverse event occurrence, quality of life improvement, or disease activity by treatment of anti-CD20 mAb for patients with primary SS. ${ }^{46}$ Moreover, a report has demonstrated that the number of peripheral Tfh cells in patients with SS was significantly reduced by rituximab treatment. ${ }^{30}$ In the present study, the treatment with anti$\mathrm{CD} 20 \mathrm{mAb}$ in SS model mice resulted in autoimmune lesion suppression as well as Tfh and GC B-cell reduction. However, autoantibody levels in the sera of SS model mice remained unchanged by anti-CD20 mAb treatment. Furthermore, no significant correlation was observed between the number of GC cells in the spleen and the disease severity of autoimmune lesions in the SS model mice. These findings suggest that Tfh cells closely contribute to the formation of the inflammatory lesions in SS target organs. Moreover, neonatal Tx diminished T-cell maintenance in the periphery and resulted in Ascl2 up-regulation of $\mathrm{CD} 4^{+}$T cells after an increase in Tfh cells within both SS model mice and C57BL/6-WT mice. The study using $\mathrm{CD} 4^{\mathrm{Cre}} \mathrm{Bcl \sigma ^{f/fl }}$ mice demonstrated that the terminal Tfh cell differentiation is determined by Bcl6, as described previously. ${ }^{31}$ Ascl2 is a potent factor for controlling Tfh cell polarization from $\mathrm{CD} 4^{+} \mathrm{T}$ cells at the early stages during the T-cell activation process. In SS model mice, an autoimmune response may be enhanced by a promoted GC reaction contributed to by an increase of Ascl2-controlled Tfh cells.

In conclusion, the GC reaction was enhanced in SS model mice. The formation of autoimmune lesions was closely associated with the number of Tfh cells in the present model. In addition, Tfh cell-related genes, such as Ascl2, were observed to be up-regulated in SS model mice. Ascl2 is a key molecule for the pathogenesis of SS, and targeting Tfh cells could be a useful therapeutic strategy for the treatment of autoimmune diseases.

\section{Acknowledgments}

We thank Michiko Kino and Hitomi Fukui for technical assistance with the maintenance of the mouse colony.

K.O. designed and performed the experiments, analyzed the data, and prepared the manuscript; A.Y., M.Sai., A.U., M.Sat., S.K., W.S., T.T., Y.K., and R.A. designed the experiments and provided intellectual assistance; N.I. provided broad guidance in experimental design, data analysis, and manuscript preparation; all authors have read, reviewed, and approved the final manuscript.

\section{Supplemental Data}

Supplemental material for this article can be found at http://doi.org/10.1016/j.ajpath.2019.08.008. 


\section{References}

1. Johnston RJ, Poholek AC, DiToro D, Yusuf I, Eto D, Barnett B, Dent AL, Craft J, Crotty S: Bcl6 and Blimp-1 are reciprocal and antagonistic regulators of $\mathrm{T}$ follicular helper cell differentiation. Science 2009, 325:1006-1010

2. Nurieva RI, Chung Y, Martinez GJ, Yang XO, Tanaka S, Matskevitch TD, Wang YH, Dong C: Bc16 mediates the development of T follicular helper cells. Science 2009, 325:1001-1005

3. Yu D, Rao S, Tsai LM, Lee SK, He Y, Sutcliffe EL, Srivastava M, Linterman M, Zheng L, Simpson N, Ellyard JI, Parish IA, Ma CS, Li QJ, Parish CR, Mackay CR, Vinuesa CG: The transcriptional repressor Bcl-6 directs $\mathrm{T}$ follicular helper cell lineage commitment. Immunity 2009, 31:457-468

4. Crotty S: T follicular helper cell differentiation, function, and roles in disease. Immunity 2014, 41:529-542

5. Suh WK: Life of $\mathrm{T}$ follicular helper cells. Mol Cells 2015, 38: 195-201

6. Fox RI: Sjogren's syndrome. Lancet 2005, 366:321-331

7. Seror R, Theander E, Bootsma H, Bowman SJ, Tzioufas A, Gottenberg JE, Ramos-Casals M, Dorner T, Ravaud P, Mariette X, Vitali C: Outcome measures for primary Sjogren's syndrome: a comprehensive review. J Autoimmun 2014, 51:51-56

8. Ramos-Casals M, Brito-Zeron P, Siso-Almirall A, Bosch X: Primary Sjogren syndrome. BMJ 2012, 344:e3821

9. Voulgarelis M, Tzioufas AG: Current aspects of pathogenesis in Sjogren's syndrome. Ther Adv Musculoskelet Dis 2010, 2:325-334

10. Haneji N, Nakamura T, Takio K, Yanagi K, Higashiyama H, Saito I, Noji S, Sugino H, Hayashi Y: Identification of alpha-fodrin as a candidate autoantigen in primary Sjogren's syndrome. Science 1997, 276:604-607

11. Nguyen CQ, Kim H, Cornelius JG, Peck AB: Development of Sjogren's syndrome in nonobese diabetic-derived autoimmune-prone C57BL/6.NOD-Aec1Aec2 mice is dependent on complement component-3. J Immunol 2007, 179:2318-2329

12. Sumida T, Tsuboi H, Iizuka M, Nakamura Y, Matsumoto I: Functional role of M3 muscarinic acetylcholine receptor (M3R) reactive T cells and anti-M3R autoantibodies in patients with Sjogren's syndrome. Autoimmun Rev 2010, 9:615-617

13. Tong L, Koh V, Thong BY: Review of autoantigens in Sjogren's syndrome: an update. J Inflamm Res 2017, 10:97-105

14. Vitali C, Bombardieri S, Jonsson R, Moutsopoulos HM, Alexander EL, Carsons SE, Daniels TE, Fox PC, Fox RI, Kassan SS, Pillemer SR, Talal N, Weisman MH; European Study Group on Classification Criteria for Sjogren's Syndrome: Classification criteria for Sjogren's syndrome: a revised version of the European criteria proposed by the American-European Consensus Group. Ann Rheum Dis 2002, 61:554-558

15. Maehara T, Moriyama M, Hayashida JN, Tanaka A, Shinozaki S, Kubo Y, Matsumura K, Nakamura S: Selective localization of T helper subsets in labial salivary glands from primary Sjogren's syndrome patients. Clin Exp Immunol 2012, 169:89-99

16. Szabo K, Papp G, Barath S, Gyimesi E, Szanto A, Zeher M: Follicular helper $\mathrm{T}$ cells may play an important role in the severity of primary Sjogren's syndrome. Clin Immunol 2013, 147:95-104

17. Jin L, Yu D, Li X, Yu N, Li X, Wang Y, Wang Y: CD4+CXCR5+ follicular helper $\mathrm{T}$ cells in salivary gland promote B cells maturation in patients with primary Sjogren's syndrome. Int J Clin Exp Pathol 2014, 7:1988-1996

18. Szabo K, Papp G, Szanto A, Tarr T, Zeher M: A comprehensive investigation on the distribution of circulating follicular $\mathrm{T}$ helper cells and B cell subsets in primary Sjogren's syndrome and systemic lupus erythematosus. Clin Exp Immunol 2016, 183:76-89

19. Saito M, Otsuka K, Ushio A, Yamada A, Arakaki R, Kudo Y, Ishimaru N: Unique phenotypes and functions of follicular helper T cell and regulatory T cell in Sjogren's syndrome. Curr Rheumatol Rev 2017, 14:239-245

20. Papageorgiou A, Voulgarelis M, Tzioufas AG: Clinical picture, outcome and predictive factors of lymphoma in Sjgren syndrome. Autoimmun Rev 2015, 14:641-649

21. Quartuccio L, Isola M, Baldini C, Priori R, Bartoloni Bocci E, Carubbi F, Maset M, Gregoraci G, Della Mea V, Salvin S, De Marchi G, Luciano N, Colafrancesco S, Alunno A, Giacomelli R, Gerli R, Valesini G, Bombardieri S, De Vita S: Biomarkers of lymphoma in Sjogren's syndrome and evaluation of the lymphoma risk in prelymphomatous conditions: results of a multicenter study. J Autoimmun 2014, 51:75-80

22. Johnsen SJ, Gudlaugsson E, Skaland I, Janssen EA, Jonsson MV, Helgeland L, Berget E, Jonsson R, Omdal R: Low protein A20 in minor salivary glands is associated with lymphoma in primary Sjogren's syndrome. Scand J Immunol 2016, 83:181-187

23. Heacke EA, Van der Vegt B, Vissink A, Spijkervet FKL, Bootsma H, Kroese FGM: Standardisation of the detection of germinal centres in salivary gland biopsies of patients with primary Sjögren's syndrome is needed to assess their clinical relevance. Ann Rheum Dis 2018, $77: \mathrm{e} 32$

24. Li XY, Wu ZB, Ding J, Zheng ZH, Li XY, Chen LN, Zhu P: Role of the frequency of blood CD4(+) CXCR5 (+) CCR6(+) T cells in autoimmunity in patients with Sjogren's syndrome. Biochem Biophys Res Commun 2012, 422:238-244

25. Fonseca VR, Romão VC, Agua-Doce A, Santos M, López-Presa D, Ferreira AC, Fonseca JE, Graca L: The ratio of blood T follicular regulatory cells to $\mathrm{T}$ follicular helper cells marks ectopic lymphoid structure formation while activated follicular helper T cells indicate disease activity in primary Sjögren's syndrome. Arthritis Rheumatol 2018, 70:774-784

26. Szabo K, Papp G, Dezso B, Zeher M: The histopathology of labial salivary glands in primary Sjogren's syndrome: focusing on follicular helper $\mathrm{T}$ cells in the inflammatory infiltrates. Mediators Inflamm 2014, 2014:631787

27. Kaji T, Ishige A, Hikida M, Taka J, Hijikata A, Kubo M, Nagashima T, Takahashi Y, Kurosaki T, Okada M, Ohara O, Rajewsky K, Takemori T: Distinct cellular pathways select germlineencoded and somatically mutated antibodies into immunological memory. J Exp Med 2012, 209:2079-2097

28. Kohashi M, Ishimaru N, Arakaki R, Hayashi Y: Effective treatment with oral administration of rebamipide in a mouse model of Sjogren's syndrome. Arthritis Rheum 2008, 58:389-400

29. Haneji N, Hamano H, Yanagi K, Hayashi Y: A new animal model for primary Sjogren's syndrome in NFS/sld mutant mice. J Immunol 1994, 153:2769-2777

30. Verstappen GM, Kroese FG, Meiners PM, Corneth OB, Huitema MG, Haacke EA, van der Vegt B, Arends S, Vissink A, Bootsma H, Abdulahad WH: B cell depletion therapy normalizes circulating follicular th cells in primary Sjogren syndrome. J Rheumatol 2017, 44:49-58

31. Liu X, Chen X, Zhong B, Wang A, Wang X, Chu F, Nurieva RI, Yan X, Chen P, van der Flier LG, Nakatsukasa H, Neelapu SS, Chen W, Clevers H, Tian Q, Qi H, Wei L, Dong C: Transcription factor achaete-scute homologue 2 initiates follicular T-helper-cell development. Nature 2014, 507:513-518

32. Choi YS, Yang JA, Crotty S: Dynamic regulation of Bcl6 in follicular helper CD4 T (Tfh) cells. Curr Opin Immunol 2013, 25:366-372

33. Brokstad KA, Fredriksen M, Zhou F, Bergum B, Brun JG, Cox RJ, Skarstein K: T follicular-like helper cells in the peripheral blood of patients with primary Sjogren's syndrome. Scand J Immunol 2018, 88:e12679

34. Gong YZ, Nititham J, Taylor K, Miceli-Richard C, Sordet C, Wachsmann D, Bahram S, Georgel P, Criswell LA, Sibilia J, Mariette X, Alsaleh G, Gottenberg JE: Differentiation of follicular helper T cells by salivary gland epithelial cells in primary Sjogren's syndrome. J Autoimmun 2014, 51:57-66 
35. Rao DA: T cells that help B cells in chronically inflamed tissues Front Immunol 2018, 9:1924

36. Yamada A, Ushio A, Arakaki R, Tsunematsu T, Kudo Y, Hayashi Y, Ishimaru N: Impaired expansion of regulatory $\mathrm{T}$ cells in a neonatal thymectomy-induced autoimmune mouse model. Am J Pathol 2015, 185:2886-2897

37. Jubb AM, Chalasani S, Frantz GD, Smits R, Grabsch HI, Kavi V, Maughan NJ, Hillan KJ, Quirke P, Koeppen H: Achaete-scute like 2 (ascl2) is a target of Wnt signalling and is upregulated in intestinal neoplasia. Oncogene 2006, 25:3445-3457

38. Kim SM, Kwon JE, Park JS, Seo HB, Jung KA, Moon YM, Lee J, Kwok SK, Cho ML, Park SH: Achaete-scute complex homologue 2 accelerates the development of Sjogren's syndrome-like disease in the NOD/ShiLtJ mouse. Immunol Lett 2017, 190:26-33

39. Corsiero E, Nerviani A, Bombardieri M, Pitzalis C: Ectopic lymphoid structures: powerhouse of autoimmunity. Front Immunol 2016, 7:430

40. Theander E, Vasaitis L, Baecklund E, Nordmark G, Warfvinge G, Liedholm R, Brokstad K, Jonsson R, Jonsson MV: Lymphoid organisation in labial salivary gland biopsies is a possible predictor for the development of malignant lymphoma in primary Sjogren's syndrome. Ann Rheum Dis 2011, 70:1363-1368
41. Kobayashi M, Yasui N, Ishimaru N, Arakaki R, Hayashi Y: Development of autoimmune arthritis with aging via bystander $\mathrm{T}$ cell activation in the mouse model of Sjögren's syndrome. Arthritis Rheum 2004, 50:3974-3984

42. Ushio A, Arakaki R, Otsuka K, Yamada A, Tsunematsu T, Kudo Y, Aota K, Azuma M, Ishimaru N: CCL22-producing resident macrophages enhance $\mathrm{T}$ cell response in Sjögren's syndrome. Front Immunol 2018, 9:2594

43. Arakaki R, Eguchi H, Yamada A, Kudo Y, Iwasa A, Enkhmaa T, Hotta F, Mitamura-Aizawa S, Mitamura Y, Hayashi Y, Ishimaru N: Anti-inflammatory effects of rebamipide eyedrop administration on ocular lesions in a murine model of primary Sjögren's syndrome. PLoS One 2014, 9:e98390

44. Ushio A, Arakaki R, Eguchi H, Hotta F, Yamada A, Kudo Y, Ishimaru N: Pathological analysis of ocular lesions in a murine model of Sjögren's syndrome. Int J Mol Sci 2017, 18:E1209

45. Bowman SJ: Primary Sjogren's syndrome. Lupus 2018, 27:32-35

46. Souza FB, Porfirio GJ, Andriolo BN, Albuquerque JV, Trevisani VF: Rituximab effectiveness and safety for treating primary Sjogren's syndrome (pss): systematic review and meta-analysis. PLoS One 2016, 11:e150749 